\title{
CES
}

COOPERATIVISMO E ECONOMÍA SOCIAL

Núm. 40 (2017-2018), páxs. 385-395

ISSN: 1130-2682

\section{UNA NUEVA REFORMA DE LAS SECCIONES DE CRÉDITO DE LAS COOPERATIVAS EN LA COMUNIDAD AUTÓNOMA DE CATALUÑA}

\section{A NEW REFORM OF THE CREDIT SECTIONS OF COOPERATIVES IN THE AUTONOMOUS COMMUNITY OF CATALONIA}

\author{
José Antonio RodRíguez MíGueZ*
}

* Doctor en Derecho. Miembro del IDIUS y CERGI, de la USC. Dirección de correo electrónico: jarmiguez@gmail.com 


\title{
RESUMEN
}

Las consecuencias de la crisis económica y financiera han sido especialmente graves para las secciones de crédito de las cooperativas hasta el punto de amenazar la propia supervivencia de las cooperativas. Con esta regulación se trata de garantizar la supervivencia de las secciones de crédito de las cooperativas agrarias de primer grado, ofreciendo una regulación más detallada y dirigida a incrementar su solvencia y continuidad.

Palabras clave: Cooperativas, economía social, secciones de crédito.

\begin{abstract}
The consequences of the economic and financial crisis have been especially serious for the credit sections of the cooperatives to the point of threatening the very survival of the cooperatives. This regulation seeks to guarantee the survival of the credit sections of first-degree agricultural cooperatives, offering a more detailed regulation aimed at increasing their solvency and continuity.

KEY wORDS: Cooperatives, Social Economy, credit sections.
\end{abstract}


SUMARIO: 1. UNA NECESARIA REMISIÓN AL CONTEXTO. 2. ESTRUCTURA Y ALCANCE DE LA NORMA. 3. CONTENIDO DE LA NUEVA REGULACIÓN: LAS PRINCIPALES MODIFICACIONES INTRODUCIDAS. 3.1. Disposiciones generales. 3.2. Regulación económica y financiera. 3.3. Contabilidad, auditoría, inspección y régimen sancionador. 3.4. El Fondo cooperativo de apoyo a las secciones de crédito. 3.5. Disposiciones complementarias. 4. VALORACIÓN FINAL.

CONTENTS: 1. A NECESSARY REFERENCE TO THE CONTEXT. 2. STRUCTURE AND SCOPE OF THE STANDARD. 3. CONTENT OF THE NEW REGULATION: THE MAIN MODIFICATIONS INTRODUCED. 3.1. General provisions. 3.2. Economic and financial regulation. 3.3. Accounting, auditing, inspection and sanctioning regime. 3.4. The Cooperative Fund to support the credit sections. 3.5. Supplementary provisions. 4. FINAL ASSESSMENT.

\section{UNA NECESARIA REMISIÓN AL CONTEXTO}

$\int$ út a Comunidad Autónoma de Cataluña ha sido especialmente activa en los últimos años en materia de cooperativas. Las sucesivas reformas, tanto de rango legal como reglamentario, llevadas a cabo en su regulación en ejercicio de las competencias asumidas por dicha Comunidad Autónoma en el marco estatutario revelan de manera clara no sólo la importancia de la denominada Economía Social en la economía de la región, sino también la preocupación que en los poderes públicos han suscitado los efectos negativos que como consecuencia de la reciente crisis económica y financiera se han advertido en el sector, comprometiendo incluso su propia supervivencia.

La norma objeto del presente comentario, la nueva Ley 7/2017, de 2 de junio, del régimen de las secciones de crédito de las cooperativas (en adelante, "Ley 7/2017, de 2 de junio" o simplemente "Ley 7/2017") $)^{1}$ debe enmarcarse en consecuencia en el referido contexto, valorando los cambios introducidos teniendo en consideración no sólo la vigente Ley 12/2015, de 9 de julio, de cooperativas (de Cataluña $)^{2}$ que configura la regulación principal en materia de cooperativas en Cataluña, sino también, en el tema específico de las "secciones de crédito", dos normas derogadas de manera expresa por la nueva Ley 7/2017. Nos referimos a la Ley 6/1998, de 13 de mayo, de regulación del funcionamiento de las secciones de crédito de las cooperativas en Cataluña ${ }^{3}$ y el posterior Decreto-ley 2/2016, de 17 de mayo, de modificación de la Ley 6/1998, de 13 de mayo, de regulación del

\footnotetext{
1 Vid. DOGC n ${ }^{\circ} 7386$, de 8 de junio de 2017 y, ulteriormente, BOE $n^{\circ}$ 160, des 6 de julio de 2017.

2 BOE n' 194, de 14 de agosto de 2015.

3 BOE nº 153, del sábado 25 de junio de 2016.
} 
funcionamiento de las secciones de crédito de las cooperativas en Cataluña ${ }^{4}$, que introdujo en la citada Ley 6/1998 un nuevo capítulo, el Capítulo IV, destinado a la creación de un "Fondo cooperativo de apoyo a las secciones de crédito5. La nueva Ley 7/2017 avanza en la línea marcadas por sus predecesoras con el objeto específico de garantizar la viabilidad de las secciones de crédito de las cooperativas.

El propósito de la nueva norma y el contexto en el que se aprueba se infiere directamente de alguna de tas afirmaciones del Preámbulo de la nueva Ley 7/2017. Así, en dicho Preámbulo podemos leer, entre otras argumentos que justifican su aprobación, los siguientes:

"La regulación de las secciones de crédito de las cooperativas se inserta dentro del bloque de legislación que tiene por objeto el buen funcionamiento del sector cooperativo y la protección del cooperativista individual.

Las secciones de crédito gestionan la tesorería de los socios comunes y los socios colaboradores de la cooperativa, que proviene de los ahorros de las unidades familiares de las zonas rurales donde están arraigadas, conjuntamente con la tesorería de la propia cooperativa, y también realizan los pagos y cobros recurrentes.

La crisis económica y financiera general de estos últimos ejercicios ha conllevado una reducción de los márgenes financieros que ha implicado, entre otros efectos, que los rendimientos de los activos financieros en que las secciones de crédito invierten sus disponibilidades sean a menudo muy ajustados para cubrir la remuneración de los saldos acreedores de la sección de crédito a sus socios titulares más sus gastos de gestión, lo que debilita, en algunos casos, la estructura financiera y económica de la cooperativa.

No poder acompasar la exigibilidad de los saldos acreedores de la sección de crédito al ritmo de liquidación ordenada de sus activos y necesitar más tiempo para poderlos liquidar puede generar un riesgo de eventuales insuficiencias de liquidez para afrontar con éxito el retorno de estos saldos acreedores a sus socios titulares, aparte del riesgo de solvencia por la actividad de la cooperativa, incluida la propia sección de crédito $^{6}$. En casos recientes, el riesgo de liquidez no se ha podido cubrir, como en el pasado, recurriendo a las entidades bancarias. Estas

\footnotetext{
4 BOE nº 153, del sábado 25 de junio de 2016.

5 Tanto la Ley de cooperativas de Cataluña como el Decreto-ley 2/2016 fueron ya objeto de su correspondiente reseña en esta misma Revista. Vid. RODRÍGUEZ MIGUEZ, J. A.; "La Nueva Ley de Cooperativas de Cataluña", en CES 35 (2015-2016), págs. 405 a 414 y, del mismo autor, "Reforma del funcionamiento de las secciones de crédito de las cooperativas en Cataluña", en CES 39 (2016-2017), págs. 411 a 420 .

6 Énfasis añadido.
} 
no han mostrado interés en dar la financiación suficiente a la cooperativa ni en adquirir la cartera crediticia otorgada por la sección de crédito, a pesar de la posibilidad de disponer de aval público.

(...)

Por lo tanto, es imprescindible estructurar un nuevo instrumento en manos de las propias cooperativas con sección de crédito que contribuya al retorno de los saldos acreedores de las secciones de crédito a los socios titulares, dotando de tiempo a la cooperativa en reestructuración para poder liquidar de forma ordenada los activos de la sección de cré$\operatorname{dito}^{7} .(\ldots)$

En consecuencia, la existencia de eventuales insuficiencias de liquidez en los procesos de baja de algunas secciones de crédito con falta de ofertas de financiación bancaria, y el correspondiente riesgo de contagio al resto de cooperativas, a pesar de tener una estructura financiera y económica adecuada, justifican ${ }^{8}$ (...)

Debe modificarse, pues, la normativa catalana en materia de secciones de crédito en este sentido, con la creación de dicho fondo de apoyo financiero ["Fondo cooperativo de apoyo a las secciones de crédito"], para profundizar en la preservación de los saldos acreedores de las secciones de crédito y, por lo tanto, de los intereses de sus usuarios, sin olvidar que las secciones de crédito de las cooperativas agrarias no son entidades financieras y que, por lo tanto, estos saldos acreedores no están cubiertos por el Fondo de garantía de depósitos de entidades de crédito ni por el Fondo de garantía de inversiones ${ }^{9}$.

Asimismo, se introducen en la normativa catalana en materia de secciones de crédito medidas para mejorar la transparencia de la actividad de la sección de crédito ante sus usuarios ${ }^{10},(\ldots)$ ".

La evidencia es, pues, que existe un problema importante en el funcionamiento de las secciones de crédito de las cooperativas agrarias que, aunque en principio, incumbe en primer lugar a las mismas por su naturaleza privada y no pública, exige un tratamiento singular por parte de los poderes públicos atendiendo, precisamente, a su singular naturaleza enmarcada en la denominada "Economía Social". El propio Preámbulo lo recuerda, repitiendo una idea ya incluida en el Preámbulo (que no "Exposición de Motivos") del Decreto-ley 2/2016, cuando afirmaba con rotundidad que:

\footnotetext{
7 Énfasis añadido.

8 Énfasis añadido.

9 Énfasis añadido.

${ }^{10}$ Énfasis añadido.
} 
“(...) hay que considerar que los perjuicios ocasionados por estas situaciones de riesgo en alguna cooperativa con sección de crédito deben ser asumidos en primer lugar por la propia cooperativa (socios y acreedores) y, en segundo lugar, por el sector, procurando la salvaguardia en todo momento del valor de las aportaciones que realicen las cooperativas con sección de crédito, pero debe evitarse que repercutan en el contribuyente o que corran a cargo de los recursos públicos."

Desde esta perspectiva vamos a abordar, de modo necesariamente sumario, el contenido de la nueva norma, la Ley 7/2017, y el alcance de los cambios introducidos.

\section{ESTRUCTURA Y ALCANCE DE LA NORMA}

La Ley 7/2017 contiene treinta y siete artículos, estructurados en cuatro capítulos (Disposiciones generales, Regulación económica y financiera, Contabilidad, auditoría, inspección y régimen sancionador y Fondo cooperativo de apoyo a las secciones de crédito), una disposición adicional, dos disposiciones transitorias, una disposición modificativa (que modifica de modo puntual la Ley 12/2015, de cooperativas), una disposición derogatoria y dos disposiciones finales.

Como ya anticipamos, la nueva norma deroga de forma expresa la Ley 6/1998, de 13 de mayo, de regulación del funcionamiento de las secciones de crédito de las cooperativas ${ }^{11}$, y el Decreto-ley 2/2016, de 17 de mayo, que modificaba la citada Ley 6/1998.

El Legislador autonómico no ha optado, en esta ocasión por modificar nuevamente la ley que estaba vigente, como había hecho en 2016, sino decidió acometer una reforma integral de la norma, reemplazándola por una nueva. Una opción de política normativa que, en consecuencia, al incorporar un Preámbulo y no una Exposición de Motivos, hace que en esta fundamental parte de la disposición se eluda una justificación más detallada de los cambios concretos introducidos, que en algún aspecto son, como veremos, relevantes y que deben apreciarse comparando la norma nueva con la derogada.

\footnotetext{
${ }^{11}$ BOE n ${ }^{\circ}$ 144, de 17 de junio de 1998. La Ley 6/1998, de 13 de mayo, de regulación del funcionamiento de las secciones de crédito de las cooperativas [en Cataluña] no era la primera norma con rango legal específica para esta singular y delicada materia. La Ley 6/1998t tiene su antecedente inmediato en la Ley 1/1985, de 14 de enero, reguladora del funcionamiento de las secciones de crédito de las cooperativas [de Cataluña].
} 


\section{CONTENIDO DE LA NUEVA REGULACIÓN: LAS PRINCIPALES MODIFICACIONES INTRODUCIDAS}

En este epígrafe destacaremos únicamente los aspectos más sobresalientes de la nueva regulación.

\subsection{Disposiciones generales}

La primera de las Disposiciones generales (Art. 1 Ley 7/2017) hace referencia al concepto y objeto de las secciones de crédito.

Conforme a la nueva norma, se deben reputar secciones de crédito a "las unidades económicas y contables internas de las cooperativas de clase agraria de primer grado ${ }^{12}$ que cumplen los requisitos establecidos por la presente ley y por la Ley de cooperativas."

Debe subrayarse en este punto que la nueva redacción del artículo 1 dedicado en el texto de 1998 al "Concepto y funciones" y en la actualidad al "Concepto y objeto" limita el concepto de sección de crédito y, con ello, la posibilidad de que una cooperativa se dote de ella a las "cooperativas de clase agraria de primer grado". En coherencia, debe entenderse que sólo este tipo de cooperativas podrán disponer de secciones de crédito ${ }^{13}$.

Se aprecia también una nueva delimitación del ámbito subjetivo de sus funciones, pues conforme a la nueva regulación, las secciones de crédito deben limitarse a la gestión de operaciones activas y pasivas dentro de la propia cooperativa a los socios comunes y a los socios colaboradores. Piénsese que la redacción equivalente de la Ley 6/1998 les permitía operar con "los socios y adheridos" y los "miembros de la comunidad familiar afectos a la actividad económica de los socios" (Art. 1 Ley 6/1998).

Tal limitación se traslada, en consecuencia, a su objeto, que ahora queda limitado a cumplir alguna de las siguientes finalidades:

“a) Contribuir a la financiación de las operaciones de la cooperativa.

b) Contribuir a la financiación de actividades de los socios comunes vinculadas a la actividad de la cooperativa o a las necesidades domésticas de los socios comunes y de los socios colaboradores.

c) Gestionar de forma conjunta las disponibilidades líquidas de los socios comunes y de los socios colaboradores."

\footnotetext{
${ }^{12}$ Énfasis añadido.

${ }^{13}$ Téngase en cuenta que el Decreto-ley 2/2016 preveía la creación del "Fondo cooperativo de apoyo a las secciones de crédito" exclusivamente a las cooperativas de clase agraria de primer grado, pero no había modificado el concepto de las secciones de crédito que ahora se circunscribirse únicamente a este tipo de cooperativas.
} 
Asimismo se prohíbe de forma expresa la existencia de unidades diferenciadas dentro de la cooperativa con finalidades asimilables a las establecidas por la presente ley para las secciones de crédito, manteniéndose que dichas secciones carecen personalidad jurídica propia, distinta de la cooperativa que se crean.

Respecto de los socios de las cooperativas con sección de crédito, conforme a su Art. 2 Ley 7/2017, cuando los socios comunes de las cooperativas rurales que, a los efectos esta ley y de la normativa que ulteriormente la desarrolla, no cumplan los requisitos para ser socios comunes en una cooperativa de clase agraria se les asimila a socios colaboradores. Del mismo modo se reputan también como socios comunes: a) los miembros de la comunidad familiar que tengan una relación de afinidad o de consanguinidad de primer grado con los socios que cumplen los requisitos legales para tener la condición de socio común en una cooperativa agraria y que lleven a cabo una actividad económica que dependa o sea afecta a la actividad económica de estos socios; b) los trabajadores de la cooperativa y c) las personas jubiladas que, en sus tres últimos años de vida profesional activa, habían tenido la condición de socio común en una cooperativa agraria.

La denominación de "sección de crédito", conforme al Art. 3 Ley 7/2017, solamente podrá ser utilizada por las cooperativas con sección de crédito que sujeten su funcionamiento a las prescripciones de la propia Ley $7 / 2017$ y cuyos estatutos prevean la existencia de una unidad interna con las finalidades establecidas por dicha ley.

En lo que atañe al registro, su regulación es más detallada (Art. 4 Ley 7/2017) que la anterior, manteniéndose su carácter obligatorio y la existencia de una sección especial dentro del Registro general de cooperativas. No obstante, en la nueva regulación se exige un informe preceptivo, vinculante y favorable del departamento competente en materia de economía y finanzas, así como que las cooperativas que soliciten el alta de una sección de crédito deban acompañar la solicitud del informe, de las cuentas anuales auditadas de la cooperativa del último ejercicio contable cerrado y, adicionalmente, de un balance auditado en la fecha de la asamblea general que acordó la creación de la sección de crédito siempre que hayan transcurrido más de seis meses entre la fecha de cierre del último ejercicio y dicha fecha de la asamblea general.

Debe destacarse también la más detallada regulación de los requisitos exigibles para sumir la gestión de dichas secciones, siendo expresivo a este respecto el título del artículo que los regula, el art. 4 Ley 7/2017, que lleva la rúbrica de "Profesionalidad de la gestión".

\subsection{Regulación económica y financiera}

El capítulo II (Arts. 6 a 12 Ley 7/2017) se ocupa de la Regulación económica y financiera de las secciones de crédito que es ahora mucho más detallada y mi- 
nuciosa en lo relativo a su estructura financiera y actividad (Art. 6 Ley 7/2017), las operaciones con la cooperativa (art. 7 Ley 7/2017) las operaciones con socios (Art. 8 Ley 7/2017), la instrumentación de las operaciones con socios (Art 9 Ley 7/2017), las facultades de los órganos sociales con relación a la actividad financiera (Art. 10 Ley 7/2017), las obligaciones de información (Art. 11 Ley 7/2017) y la exigibilidad de los saldos acreedores (Art. 12 Ley 7/2017).

\subsection{Contabilidad, auditoría, inspección y régimen sancionador}

El Capítulo III (arts. 13 a 23 Ley 7/2017) se ocupa de las normas específicas en materia de contabilidad, auditoría, inspección y régimen sancionador. En todos estos ámbitos la regulación es mucho más amplia, dedicando la nueva normas preceptos específicos y diferenciados para el tema de la auditoria (Art. 14 Ley 7/2017), las obligaciones de comunicación de los auditores (Art. 15 Ley 7/2017) y la Inspección y órganos competentes en materia sancionadora (Art. 16 Ley 7/2017).

En materia de Responsabilidad (Art. 17 Ley 7/2017) se mantiene la pauta de extenderla a la cooperativa, y también, si es imputable a su conducta dolosa o negligente, la responsabilidad del director general o el gerente, de los miembros del consejo rector y de los interventores de cuentas.

Asimismo se establece un régimen de Infracciones (Art. 18 Ley 7/2017), Sanciones aplicables a las cooperativas (Art. 19 Ley 7/2017) y las aplicables a "a otros sujetos" 14 (Art. 20 Ley 7/2017). En los Arts. 21 a 23 Ley 7/2017 se regulan las Competencias sancionadoras, las Normas de procedimiento y la Normativa supletoria.

\subsection{El Fondo cooperativo de apoyo a las secciones de crédito}

El Capítulo IV, como ocurría en la Ley 6/1998 tras la reforma de 2016, está dedicado al "Fondo cooperativo de apoyo a las secciones de crédito" (en adelante el "Fondo"), figura que se mantiene en consecuencia. No obstante, su regulación es ahora más detallada:

La Ley 7/2017 incorpora a su contenido normativo — pues en el Decreto-ley 2/2016 aparecía sólo en el Preámbulo - la finalidad básica del Fondo que no es otra que "dar estabilidad y sostenibilidad al conjunto de las cooperativas con sección de crédito." (Art. 24.1 Ley 7/2017, bajo la rúbrica "Finalidad, objeto y naturaleza"), haciéndolo en términos más generales que los que incorporaba el Artículo 20 del Decreto-ley 2/2016 que circunscribía su objeto a "contribuir al retorno a sus titulares los fondos constituidos como saldos acreedores a las sec-

${ }^{14}$ El artículo 16 de la Ley 6/1998 hablaba de "Otras sanciones". 
ciones de crédito, siempre que los socios hayan acordado la baja de la sección de crédito correspondiente antes de recibir el mencionado soporte financiero." Dicho objeto es descrito ahora como el de "contribuir a devolver a sus titulares los fondos constituidos como saldos acreedores en las secciones de crédito, siempre que los socios hayan acordado la baja de la sección de crédito correspondiente antes de recibir una actuación de apoyo financiero ${ }^{15}$."

No es posible entrar en el detalle de la nueva regulación del Fondo, que resulta mucho más minuciosa, pues se regulan aspectos como la Participación en el mismo (Art. 25); la Recuperación del valor de las participaciones (Art. 26); su Administración (Art. 27); su Órgano rector (Art. 28); las Comisión delegada y su composición (Arts. 29 y 30); el Régimen económico (Art. 31); las Aportaciones no integrables a capital de cada cooperativa con sección de crédito (Art. 32); las posibles Actuaciones de apoyo financiero (Art. 33); los Criterios con relación a las actuaciones de apoyo financiero (Art. 34); el Destino de la parte del Fondo no aplicada a actuaciones de apoyo financiero (Art. 35), las Cuentas anuales y distribución del resultado (Art. 36) y la Colaboración y deber de secreto (Art. 37).

Como hemos indicado, buena parte de estas previsiones ya aparecían en la regulación de 2016, pero ahora se tratan de forma individualizada y más pormenorizada.

\subsection{Disposiciones complementarias}

La Disposición adicional única crea la Comisión de Seguimiento Sectorial de Cooperativas con Sección de Crédito como órgano colegiado de consulta, colaboración y asesoramiento, con carácter no vinculante, de la Administración de la Generalidad. Dicha Comisión se adscribe al departamento competente en materia de economía y finanzas y participada por los departamentos de la Generalidad competentes en materias relacionadas con el cooperativismo, la agricultura y las secciones de crédito y por el sector cooperativo agrario.

La Comisión tiene como funciones generales la consulta, el asesoramiento y el seguimiento del sector cooperativo agrario con sección de crédito y debe acordar su régimen de funcionamiento y su composición.

El régimen transitorio tiene por objeto la acreditación de conocimientos del director general o gerente de las cooperativas y se regula la situación de los requerimientos emitidos en virtud del Decreto ley 2/2016.

La Disposición modificativa ya aludida tiene por objeto la modificación de la Ley 12/2015, de cooperativas, introduciendo, concretamente la letra f) del apartado 3 del artículo 150 de dicha la Ley 12/2015, en materia de infracciones.

${ }^{15}$ Énfasis añadido. 
Finalmente y junto a la Disposición derogatoria ya comentada, en las dos disposiciones finales se prevé las normas para desarrollar reglamentariamente la Ley 7/2017 y su entrada en vigor.

\section{VALORACIÓN FINAL}

La nueva norma introduce notables cambios en la normativa reguladora de las secciones de crédito tratando de este modo de garantizar su mantenimiento en un contexto económico que continúa a ser difícil para las mismas.

La nueva norma sigue la senda del Decreto-ley $2 / 2016$, centrada en dar solución a los problemas financieros que atravesaban las cooperativas agrarias. La nueva ley centra en ellas la regulación general de las secciones de crédito que, a su amparo, serían las únicas que podrían constituir secciones de crédito. 